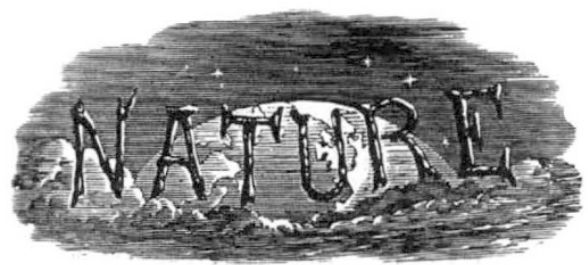

THURSDAY, MARCH 2, I922.

Editorial and Publishing Offices:

MACMILLAN \& CO., LTD.,

ST. MARTIN'S STREET, LONDON, W.C.2.

\begin{abstract}
Advertisements and business letters should be addressed to the Publishers.

Editorial communications to the Editor.

Telegraphic Address: PHUSIS, LONDON.

Telephone Number: GERRARD 8830.
\end{abstract}

\section{Cycles in the Yield of Crops.}

$\mathrm{N}$

EARLY five-and-twenty years have elapsed since Sir Arthur Schuster, by devising the orderly and comparatively brief process known as the " periodogram method," gave a great stimulus to the investigation of periodicities in natural phenomena. Solar and magnetic phenomena provided the first fields of application, and meteorological data have since been attacked by many investigators. It seems fitting that crops, which are so largely dependent on the weather, should be submitted to the same test.

In the course of last year Prof. H. L. Moore, of Columbia University, published a series of three articles in the American Quarterly Journal of Economics, which may be briefly summarised as indicating that, in the periodogram for periods of three to twelve years, there is a marked maximum at eight years in the cycles of a number of crops and corresponding cycles in the production of the raw materials of industry. This periodicity appears to correspond to what is known as the "economic cycle" in trade, and it is suggested that the periodicity in crops is the generating cycle of the whole movement-a movement which is very clearly reflected in prices. Prof. Moore's data refer, for the most part, to the years I882-19r8 only, with the exception of Sauerbeck's data for prices in this country, which are available from $18 \mathrm{r} 8$, and of wheat prices in England, which are utilised for the years r870-r9r6. To the latter part of his third article we return briefly below.

In the meantime, in an article published in the British Economic Journal for March I920, Sir William Beveridge suggested, on evidence which, to many readers, did not seem at all adequate, the existence of a period "between $15^{\circ} 2$ and 15.4 years." In the same journal for December I92I, a further paper was published in which the original conclusion is completely vindicated. By the aid of overlapping data as to wheat prices in a large number of places in Great Britain, France, Germany, and the Netherlands, an indexnumber of wheat prices for Western Europe is constructed running from I500 to I869. The index-number for each year is then expressed as a percentage of the mean of the thirty-one years surrounding it, and the results are submitted to periodogram analysis over the three centuries $\mathrm{I} 545^{-1} \mathrm{I} 44$, for periods running from two years to thirty-six. Data are also given separately for $\mathrm{I} 545^{-1} 694$ and $\mathrm{I} 695^{-\mathrm{I}} 844$.

For the whole 300 years and for the last 150 years the greatest intensity, taking only integral periods, is at fifteen years, the maximum being well marked; for the earlier $15 \circ$ years the intensity at $x_{5}(70)$ is slightiy exceeded by the intensity at $x_{1}(76), I_{3}(80)$, and 18 (73). Testing fractional periods on the series as a whole, the intensity at $\mathrm{I}_{5}(47)$ is raised to 82 at $\mathrm{I}_{5} \frac{1}{3}$, and to 80 at $15 \frac{1}{2}$. The dominant period appears, therefore, to be fairly closely $\mathrm{r}_{5} \cdot 3$.

But, Sir William Beveridge suggests in an interesting analysis that follows, the period thus found is probably not a real one-i.e. is not the period that exists in the operative cause, the weather. If a certain cycle exists in the weather tending to give, say, abnormally heavy rain at its maximum, it will nevertheless not have any adverse influence on the harvest unless the maximum and its accompanying deluge fall within the limited period of year during which the crop is growing. Hence what will be observed in the crop is not necessarily the period of the weather cycle, but the period in which its maximum tends to recur during the critical months. We have not space to follow the author's reasoning in detail, but it is suggested that there are at least two weather cycles operating, if not four(a) with a period of approximately 4.37 years $(30.6 / 7)$, which corresponds to a cycle identified by Sir Arthur Schuster in sunspots ; $(b)$ with a period of about $5 \cdot \mathrm{II}$ years $(3 \circ 6 / 6)$, which has been found in temperature and rainfall records; and two of less certainty, $(c)$ with a period of $2 \cdot 74$ years $(30 \cdot 6 / \mathrm{II})$, and $(d)$ with a period of $3 \cdot 7$ I years, both of which also appear to have been identified in meteorological or astronomical data.

The period observed, it is argued, arises from a temporary compounding of the effects of these four cycles. All four "are due to return to a maximum phase between February and September 1923," and this may mean an exceptionally bad year for harvests in Europe. "In the excessively improbable event of my arithmetical analysis being complete and accurate in every particular," Sir William Beveridge continues No. 273 I, voL. IO9] 
" 1923 is destined to repeat something like the experiences of $\mathrm{I}^{3} \mathrm{I} 5$, the year of the worst and most general harvest failure known in European history." To the crowd, if not to the man of science, the fulfilment of a prophecy always seems to give more adequate support to a theory than any number of agreements with past events, and the year 1923 may be awaited with an interest mingled with anxiety. On the face of it, the evidence seems sound, and the reasoning careful and critical.

Sir William Beveridge does not attempt to trace the physical causation of the observed periodicity further than to show that it may be accounted for by cycles already noted in meteorological or astronomical data. The eight-year period gives only a small maximum in his periodogram with an intensity of $\mathbf{I} 2$. Years after I844 were apparently omitted in part because during the nineteenth century the character of the curve visibly alters, the "credit cycle" acting as a "disturbing influence." It may, however, be questioned, in view of Prof. Moore's work, whether the credit cycle can be treated in this way as an extraneous disturbing cause. An eight-year cycle, as he says, was isolated in the barometric pressure of the United States, and has also been traced in rainfall, and these cycles appear to be congruent with the economic cycle. When Prof. Moore goes beyond this and seeks for a cosmic cycle that may be regarded as the "generating cycle," he lights on an hypothesis for which, we think, a good deal of further evidence will be required before it can win acceptance; it is suggested that the period in question is that between conjunctions of the earth and Venus. No proof, however, is given that the periods coincide with any precision, the periodograms for economic data having been calculated only for integral periods.

Analysis must be carried further before a true consonance of the periods can be predicted with any confidence. The point brought out by Sir William Beveridge, moreover, that the period in the weather may not be that in the yield of the crop, must be borne in mind. If a "maximum" of some kind in the weather is vital to the crop only provided that it occur at some critical period of the year, the determination of this critical period becomes of interest, and we would suggest that such work as that of Mr. R. H. Hooker, of the Ministry of Agriculture, whose presidential address to the Royal Meteorological Society on the correlation in eastern England between yield and the weather in successive months of the year was summarised on p. I93 of NATURE for February 9, might help to elucidate the matter. Crop prediction is a matter of the highest economic importance, and all lines of investigation should be considered together.

\section{A Searchlight on Solids.}

Aggregation and Flow of Solids: Being the Records of an Experimental Study of the Micro-structure and Physical Properties of Solids in Various States of Aggregation, I900-192 I. By Sir George Beilby. Pp. $\mathrm{xv}+256+34$ plates. (London: Macmillan and Co., Ltd., 192x.) 20s. net.

T

HIS is a book that will hold a true child of science

like any fairy-tale, and it would be difficult to overstate its fascinating interest. In form, in substance, and in all its auspices it is so highly individual. It is a story, a connected story, of the leisure pursuits of one of our leading and most enlightened industrialists, who for many years, and pre-eminently in the stress of war, has rendered great

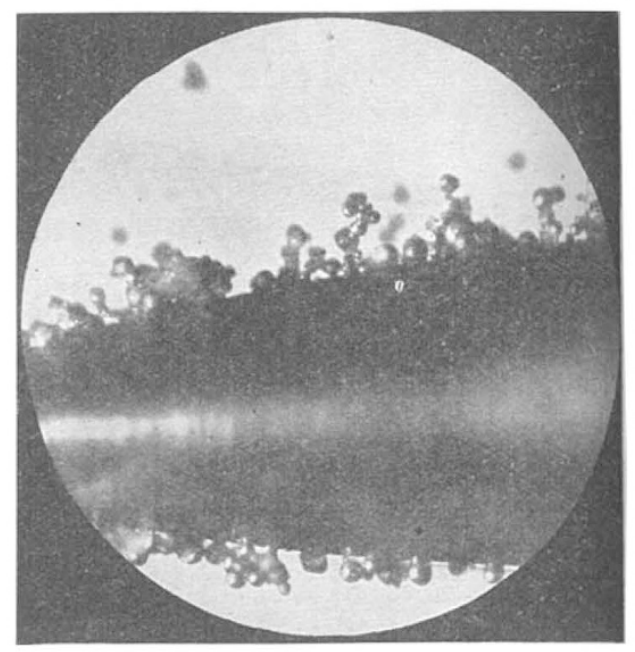

FrG. x.-Globules of zinc dust picked up on the edges of a thin steel blade $(\times 60)$. From "Aggregation and Flow of Solids."

services to his country. But it is a record that would adorn a life wholly devoted to the pursuit of science.

All who are seriously concerned with physical or chemical science must know something of the contributions which Sir George Beilby has made to the subject dealt with in this book, but the rush of scientific discovery makes it very difficult to realise the full sweep and significance of much that is going forward. Probably every one knows that Sir George Beilby has demonstrated the existence of a vitreous state in metals and other solids where that state had never been suspected, and to most of us he has become permanently "featured" on the transparent surface film of polished solids.

In his papers from time to time he has disclosed in some degree the theoretical accompaniment and the connecting threads of his experimental work, but it is probable that few will have seen the extraordinary breadth and comprehensiveness of the ideas which have developed as the work proceeded, or have realised

NO. 273 I, VOL. 109] 